УДК 528:332.83(045)

\title{
К.Г. Степанов
}

\section{ИНФОРМАТИВНОСТЬ КАДАСТРОВОГО КАРТОГРАФИРОВАНИЯ КАК ПОКАЗАТЕЛЬ КАЧЕСТВА ТЕРРИТОРИАЛЬНОГО РАЗВИТИЯ ${ }^{1}$}

\begin{abstract}
Рассматривается возможность проведения анализа качества территориального развития посредствам использования специализированного показателя информативности кадастрового картографирования. Для этого автором даётся определение содержания указанного показателя, обосновывается его применимость для достижения поставленной цели через раскрытие проблемной обусловленности его компонентов, предлагается перечень конкретных индикаторов, которые могут быть интегрированы в составе искомого показателя. В роли характеристик качества территориального развития в исследовании обозначены совокупные положительные свойства объектов недвижимости, приобретаемые ими при высоких значениях информативности кадастрового картографирования. Соответствующие характеристики описываются показателем, рассчитанным двумя разными методами, один их которых выделяется как наиболее оптимальный, ввиду большей информативности. Полученные расчётным путём результаты проанализированы на предмет их репрезентативности и возможности самостоятельного применения для изучения состояния развития территории. На основании итоговых выводов автором выдвигается тезис о том, что сформулированный и использованный в настоящей работе комплексный показатель информативности кадастрового картографирования целесообразно применять при анализе качества территориального развития совместно с другими сопоставимыми показателями, после доработки состава количественных индикаторов, формирующих содержание описанного комплексного показателя.
\end{abstract}

Ключевые слова: кадастровое картографирование, расчёт интегральных показателей, качество территориального развития, экономические свойства недвижимости.

DOI: $10.35634 / 2412-9518-2020-30-4-484-495$

Сложившаяся в России система управления земельными ресурсами и недвижимостью в целом нуждается в действенных мероприятиях по повышению эффективности её работы. В частности, потребность в улучшении данной системы во многом касается достоверности и полноты данных, описывающих объекты недвижимого имущества. Проблема качества таких данных заключается в том числе в ведомственной разобщенности государственных информационных ресурсов, содержащих разрозненные сведения о земле как объекте недвижимости и природном ресурсе, о лесах и лесных участках, водных объектах и сельскохозяйственных угодьях, и о других природных объектах. Разрозненность официальной информации о недвижимости, несогласованность её форматов и отсутствие механизмов интеграции данных ведёт к низкой эффективности использования земель и объектов капитального строительства. А это в свою очередь приводит к недоступности информации о неиспользуемых земельных ресурсах, которые можно вовлечь в хозяйственный оборот, неэффективному расходованию бюджетных средств на обработку одних и тех же данных, к рискам при принятии управленческих решений и другим негативным последствиям [1].

Для того чтобы поэтапно нивелировать вышеописанные проблемы в трёх субъектах РФ, в том числе в Иркутской области, планировалось провести эксперимент, целью которого станет создание единой интегрированной системы, объединяющей в себе множество пространственных данных, содержащихся в различных государственных информационных ресурсах. Причём базовыми для создания указанной системы станут в большей степени геоинформационные ресурсы, а именно: сведения единой электронной картографической основы, федерального фонда пространственных данных, фонда данных государственной кадастровой оценки и единого государственного реестра недвижимости $(\mathrm{EГРН})^{2}$

\footnotetext{
${ }^{1}$ Исследование выполнено в рамках НИР «Активизация внутреннего потенциала развития регионов ресурсной специализации (на примере Байкальского региона)», регистрационный номер AAAA-A17-117041250056-2, и НИР «Общественно-географические факторы безопасности регионов Сибири с позиций устойчивого развития», регистрационный номер АAАA-A19-119122490007-4.

${ }^{2}$ Проект Постановления Правительства Российской Федерации «О проведении в 2020 году эксперимента по созданию единого информационного ресурса о земле и недвижимости» (подготовлен Росреестром 30.04.2020). URL: https://regulation.gov.ru/projects\#npa=101659 (дата обращения: 28.05.2020).
} 
Последний ресурс содержит в себе сведения не только исключительно геоинформационного характера, но и производные от них - экономически обусловленные и (или) юридически значимые пространственные данные, индивидуально-определяющие, описывающие объекты недвижимости.

Такое описание имеет ряд неоспоримых положительных эффектов, находящих своё выражение в интенсификации процессов территориального развития. В частности, это напрямую касается расширения возможностей ведения бизнеса и организации государственного (муниципального) управления на принципиально ином экспертном уровне.

В связи с этим представляется целесообразным оценить, насколько репрезентативно полнота пространственного описания недвижимости в ЕГРН может отражать качественный характер развития конкретных территорий. Понимание возможностей использования показателей информативности геоданных кадастра для целей анализа, планирования и принятия решений, с учётом динамики вышеописанных интеграционных процессов может иметь высокую практическую ценность.

\section{Постановка проблемы}

Для решения обозначенной задачи первоначально необходимо определить критерии оценки наполненности профильного реестра, для чего требуется сформулировать конкретные практические проблемы, которые препятствуют достижению высокой информативности исследуемой области геоданных.

При этом необходимо учитывать, что в качестве причины отсутствия нужного объёма сведений гипотетически рассматривается невысокая информативность кадастрового картографирования в совокупности, как общая тенденция. Для целей данной работы кадастровое картографирование определяется, как финальный технический этап кадастровой деятельности, а именно - визуализация содержания её итогов, в виде отображения на кадастровой карте границ объектов учёта, последовательно, по иерархии и масштабу: объектов капитального строительства (ОКС), земельных участков, территорий муниципальных образований, субъектов федерации, государственной границы и пр.

Относительно практических проблем информативности можно сформулировать следующие укрупнённые группы таковых:

1) границы одних объектов ошибочно пересекают границы других объектов: земельных участков, ОКС, лесничеств, лесных участков, населенных пунктов и др. (например, рис. 1);

2) границы ранее учтённых объектов недвижимости ${ }^{3}$ уточнены ${ }^{4}$ некорректно;

3) границы объектов не уточнялись (не устанавливались): нормативно установленные границы объектов отсутствуют - сведения о границах ранее учтённых земельных участков и ОКС, имеющих легитимно установленного («зарегистрированного») владельца, вообще не вносились в кадастр.

Первая группа проблем во многом стала причиной тех преобразований в управлении земельно-имущественным комплексом, о которых шла речь во введении к настоящей статье, поскольку такие проблемы в основном обусловлены несоответствием имеющихся в кадастре сведений сведениям других государственных учётных систем недвижимости. Главным образом (по количеству) несоответствием государственному лесному реестру, что в свою очередь породило множество судебных исков об изъятии земельных участков, права на которые зарегистрированы за конкретными собственниками, зачастую уже не один год. В частности, в Иркутской области в отношении земельных участков, имеющих пересечения с лесным фондом, в 2016 г. от имени государства составлено около 29 тысяч исков [2].

По состоянию на июль 2017 г. согласно данным, представленным Росреестром, на территории РФ насчитывалось более 377 тысяч земельных участков, которые имеют подтвержденные пересечения с землями лесного фонда. С учетом того, что большинство лесных участков не имело точно установленных границ, и у половины иных участков также не было точных границ, то число «скрытых» пересечений по расчетам специалистов могло на тот момент достигать 2 млн [3].

\footnotetext{
${ }^{3}$ Согласно п. 4 ст. 69 Федерального закона № 218-Ф3 «О государственной регистрации недвижимости» - все объекты недвижимости, учтённые в соответствии с действовавшим в момент учёта законодательством, в период до 2007 г.

${ }^{4}$ Там же, в п. 1 ст. 43, под уточнением понимается «государственный кадастровый учет в связи с изменением описания местоположения границ земельного участка и (или) его площади».
} 


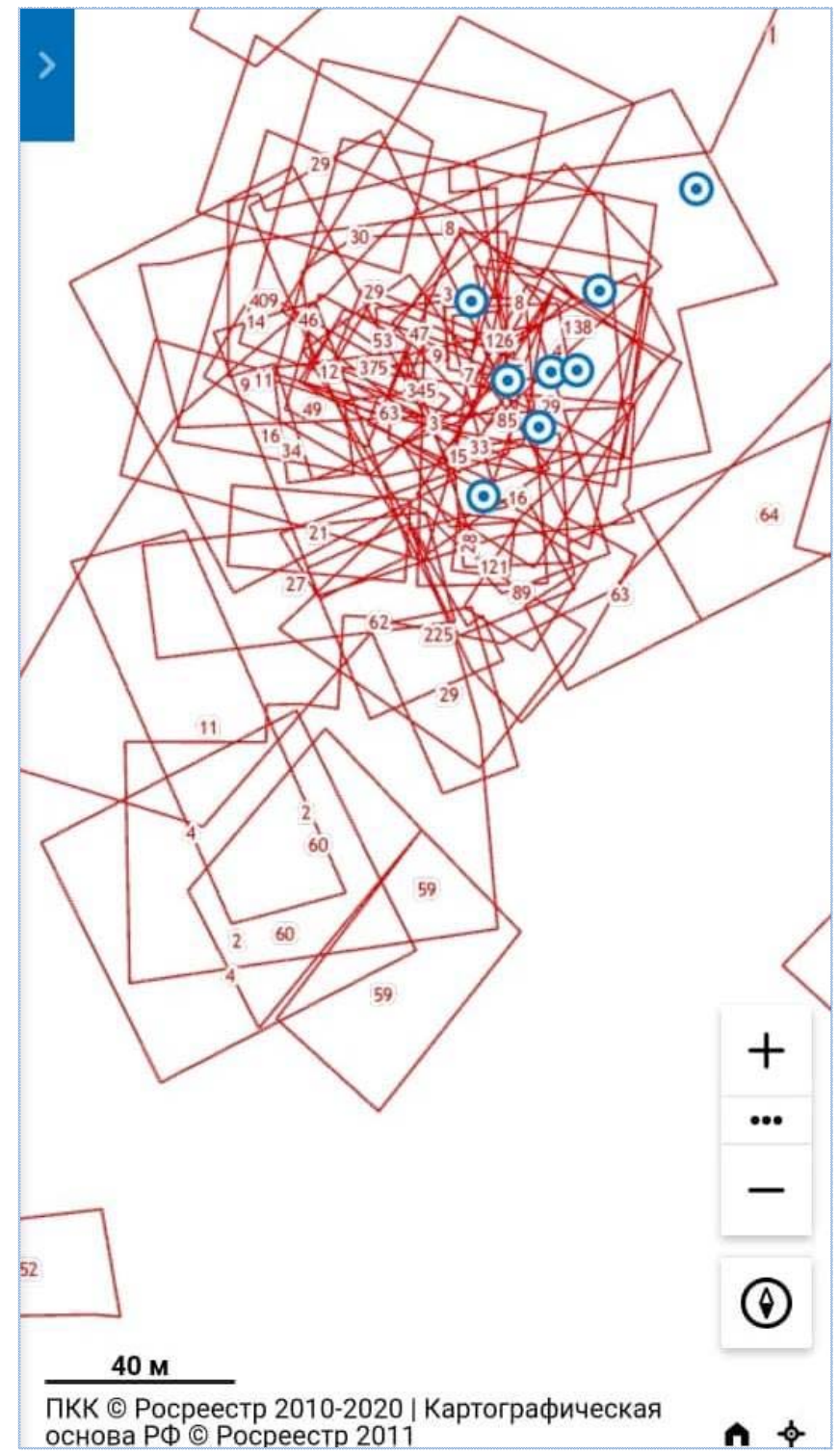

Рис. 1. Фрагмент публичной кадастровой карты Тверской области ${ }^{5}$

Действующий в настоящее время федеральный закон о «лесной амнистии» ${ }^{6}$ призванный кардинально изменить эту ситуацию в административном порядке, позволил только в Иркутской области вывести более 10 млн га лесного фонда из этой категории земель к концу 2019 г. [4]. До этого времени выбывшие площади, соответственно, имели спорный правовой статус и не могли полноценно обращаться на рынке недвижимости, эксплуатироваться иным законным способом.

Содержание второй группы проблем выражается в негативной практике кадастрового картографирования (проведения кадастровых работ), при которой на земельном участке одного правообладателя оказываются расположенными ОКС другого правообладателя (правообладателей). Причём права на такие объекты или помещения в них зарегистрированы в установленном порядке, а сведения об их границах в кадастре отсутствуют, что собственно и позволяет распространить «под них» земельный участок иного лица.

\footnotetext{
${ }^{5}$ Фрагмент публичной кадастровой карты Тверской области. URL: https://pkk.rosreestr.ru/\#/search/ 52.82029428337682,13.92075542549959/18/@470200?text=52.820258\%2013.921899\&type=1\&inPoint=true （дата обращения: 05.06.2020).

${ }^{6}$ Федеральный закон от 29 июля 2017 г. № 280-Ф3 «О внесении изменений в отдельные законодательные акты Российской Федерации в целях устранения противоречий в сведениях государственных реестров и установления принадлежности земельного участка к определенной категории земель».
} 
Например, при уточнении границ федерального земельного участка, находящегося в пользовании государственного учреждения, на таком участке оказываются расположенными: нежилые здания, находящиеся в частной собственности, многоквартирные дома, квартиры в которых приватизированы почти полностью, муниципальные автомобильные дороги общего пользования и т.п. Это становится возможным благодаря тому, что сведения о границах всех этих ОКС отсутствуют в кадастре на момент уточнения границ участка, а владелец участка не учитывает (в том числе и намеренно) то, что на нём расположены чужие постройки, находящиеся там уже длительное время [5]. В итоге с обеих сторон возникают сложности, связанные с налогообложением и реализацией своих прав на недвижимость - и на участок, и на ОКС, на этом участке расположенные.

Третья группа проблем существует в связи с тем, что уточнение границ объектов недвижимости на сегодняшний день носит необязательный характер: нормы законодательства по данному вопросу затрагивают только процедурную его сторону. Исходя из этого, абсолютно правомерной и приемлемой считается ситуация, когда в среднем по стране почти $40 \%^{7}$ земельных участков не имеет однозначных границ, а соответственно, корректной кадастровой стоимости, неоспоримого местоположения и пр.

Анализируя вышеописанные группы проблем, в контексте настоящего исследования необходимо сделать вывод о применимости тех критериев оценки информативности кадастрового картографирования, которыми обуславливаются эти проблемы. Для этого определим для каждой группы по одному критерию:

1) количество ошибочных пересечений границ;

2) количество некорректных уточнений границ;

3) количество уточненных (установленных) границ.

В отношении первого критерия можно предположить, что его применение крайне затруднительно, поскольку установить точное количественное выражение данной величины невозможно ввиду отсутствия официальной и общедоступной системы фиксации таких фактов. Кроме того, отсутствуют какие-либо широко применяемые принципы унификации подобных явлений, а их содержание весьма многообразно.

В этой связи видится возможным взять за основу по данному критерию не количество пересечений как таковых, а объём выбытий земель лесного фонда по субъектам федерации, поскольку такие сведения входят в систему официальной отчётности региональных управлений Росреестра [6]. При этом социально-экономическая важность данного показателя крайне велика, что подтверждается информацией, приведённой выше.

Относительно второго критерия следует отметить его, схожую с первым критерием, количественную проблематику, с уточнением о том, что возникающие негативные последствия в данном случае носят более частный характер, что ещё сильнее затрудняет формирование каких-либо массивов статистических данных для анализа. Имеется в виду, что владельцы земельных участков и владельцы ОКС, расположенных на них, могут по договоренности не обострять существующие противоречия, не переводя их в публичную плоскость. Следовательно, информация о фактах такого рода может быть известна только закрытому составу субъектов.

Исходя из этого, для проработки второго критерия предлагается пойти от обратного и рассматривать количество корректных (с высокой вероятностью) уточнений (определений) границ ранее неучтённых земельных участков. К ним условно можно отнести, в частности, границы участков, установленных в соответствии с утвержденными проектами межевания территории. ${ }^{8} \mathrm{~K}$ таковым, например, относятся участки под многоквартирными домами, количество которых можно оценить по данным государственной статистики, ведущейся в РФ по муниципалитетам с 2009 г., в форме отношения количества таких домов на указанных участках, к общему количеству домов. ${ }^{9}$

В отличие от двух предыдущих третий критерий намного более применим для проведения количественного анализа по нему, в части информативности, поскольку интерактивный сервис Росрее-

\footnotetext{
${ }^{7}$ Росреестр: за I квартал 2020 г. доля земельных участков с уточнёнными границами составила $60,5 \%$. URL: https://rosreestr.ru/site/press/news/rosreestr-za-i-kvartal-2020-g-dolya-zemelnykh-uchastkov-s-utochnennymigranitsami-sostavila-60-5/ (дата обращения: 24.07.2020).

${ }^{8}$ П. 3 ст. 11.3. Земельного кодекса РФ (в действующей редакции).

${ }^{9}$ Указ Президента РФ от 28 апреля 2008 г. № 607 «Об оценке эффективности деятельности органов местного самоуправления городских округов и муниципальных районов».
} 
стра - Публичная кадастровая карта, позволяет в актуальном режиме получить соответствующие данные, обособлено по любым единицам кадастрового деления, установленного в РФ.

Для исследования территории по всем трём вышеописанным критериям необходимо вычислить сводный (комплексный) показатель информативности кадастрового картографирования (ИКК). В качестве составляющих такого показателя ИКК в данной работе будут применяться следующие индикаторы по мере уменьшения масштаба описываемой ими территории:

1) доля объектов учёта с установленными границами;

2) номинальный объём выбытий земель лесного фонда по субъектам;

3)доля многоквартирных домов, расположенных на земельных участках, в отношении которых осуществлен государственный кадастровый учет.

\section{Объекты и методы исследований}

Упомянутый в предыдущем разделе официальный информационный сервис Росреестра позволяет исследовать по первому из вышеуказанных показателей любой регион России. В связи с этим для большей репрезентативности статистической выборки в качестве первоначального объекта изучения выбраны все регионы, входящие в состав Сибирского и Дальневосточного федеральных округов.

Для проведения вычислений по первому показателю, применяя метод статистической группировки и сводки, получаем следующую таблицу (табл. 1):

\section{Данные публичной кадастровой карты по состоянию на 02.02.2020}

Таблица 1

\begin{tabular}{|c|c|c|c|c|}
\hline $\begin{array}{c}\text { Наименование } \\
\text { региона } \\
\text { (субъекта РФ) }\end{array}$ & $\begin{array}{c}\text { Количество } \\
\text { учтённых } \\
\text { земельных } \\
\text { участков }\end{array}$ & $\begin{array}{c}\text { в том числе } \\
\text { с установленными } \\
\text { границами }\end{array}$ & $\begin{array}{c}\text { Количество } \\
\text { учтённых } \\
\text { ОКС }\end{array}$ & $\begin{array}{c}\text { в том числе } \\
\text { с установленными } \\
\text { границами }\end{array}$ \\
\hline Омская область & 954725 & 472229 & 429598 & 58346 \\
\hline Томская область & 505041 & 283150 & 217928 & 37949 \\
\hline Новосибирская область & 1347621 & 1007475 & 503743 & 125867 \\
\hline Алтайский край & 1766669 & 1146459 & 642172 & 93259 \\
\hline Республика Алтай & 238239 & 137248 & 78544 & 16631 \\
\hline Республика Хакасия & 357709 & 211093 & 167423 & 20907 \\
\hline Республика Тыва & 164829 & 132439 & 63400 & 28512 \\
\hline Кемеровская область & 1165234 & 562017 & 738205 & 144552 \\
\hline Красноярский край & 1820841 & 1118885 & 974994 & 140610 \\
\hline Иркутская область & 984800 & 793157 & 554422 & 117365 \\
\hline Республика Бурятия & 654956 & 590259 & 267579 & 41906 \\
\hline Забайкальский край & 528448 & 392362 & 205229 & 32010 \\
\hline Республика Саха & 554555 & 365114 & 335746 & 61045 \\
\hline Чукотский автономный & 14328 & 7814 & 21266 & 1461 \\
\hline округ & 115377 & 45162 & 45927 & 7287 \\
\hline Камчатский край & 65229 & 61583 & 26400 & 1779 \\
\hline Магаданская область & 451888 & 258838 & 204518 & 25183 \\
\hline Хабаровский край & 487406 & 251622 & 258346 & 30140 \\
\hline Амурская область & 117623 & 115201 & 43376 & 4893 \\
\hline Еврейская автономная & & 101424 & 81675 & 16369 \\
\hline область & 171336 & 421675 & 388637 & 50465 \\
\hline Сахалинская область & 801880 & 6475206 & 6249128 & 1056536 \\
\hline Приморский край & 13268734 & & & \\
\hline ИтоГО: & & & & \\
\hline
\end{tabular}

Исходя из имеющихся данных, вычисляем показатель информативности кадастрового картографирования в части установления границ объектов недвижимости, как среднее арифметическое между отношением ОКС и земельных участков, для которых установлены границы, к общему их количеству. 
Графически итоги вышеописанных расчётов представлены на рис. 2 в виде тематической карты, отражающей дифференциацию территории по рассчитанному показателю.

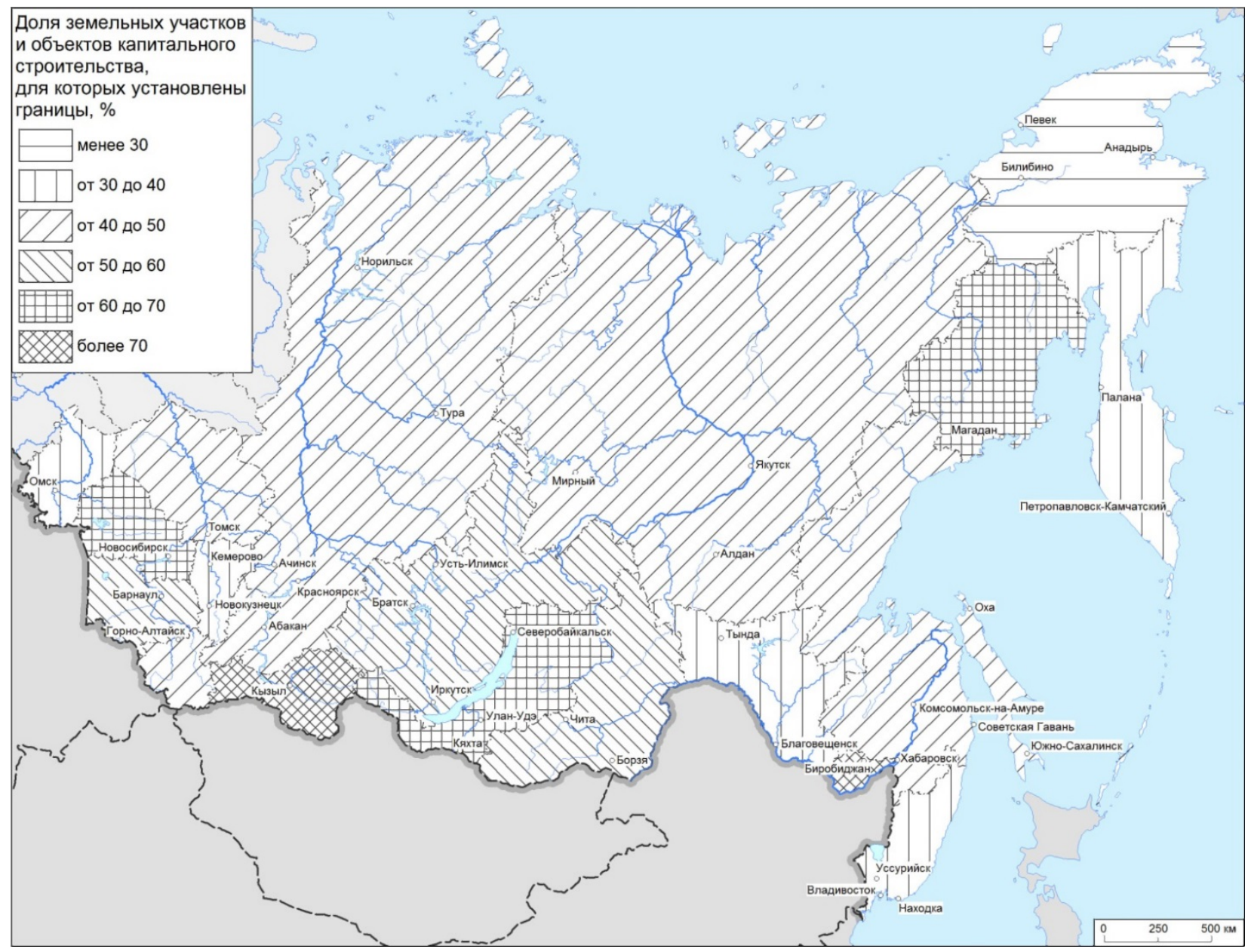

Рис. 2. Доля земельных участков и ОКС, для которых установлены границы

Из анализа картографического материала, полученного на основе произведённых вычислений, можно сделать вывод о том, что найденный показатель по двум округам будет в среднем равняться 40 \%, причём для Сибирского федерального округа (СФО) в отдельности его усреднённое значение будет таким же.

Поскольку два региона Сибирского федерального округа - Иркутская область и Красноярский край являются лидерами страны по лесным ресурсам [7], представляется обоснованным в данной работе исследовать вопрос выбытия земель лесного фонда (второй показатель информативности) в отношении регионов одного только СФО.

При этом, учитывая, что территория разных субъектов округа чаще несопоставима между собой по площади и плотности населения, результаты проводимых расчётов по регионам необходимо привести в сопоставимый вид по совокупному количеству объектов, поставленных на кадастровый учёт на изучаемой территории. Это в свою очередь даст возможность рассчитать интегральные показатели информативности кадастрового картографирования, более достоверно отображающие изучаемые процессы.

Проведенные расчёты сгруппированы в табл. 2, где сравнительный интегральный показатель по рейтинговому методу получен при помощи применения рейтингового метода трансформации частных индикаторов. В данном случае он заключается в том, что регионы ранжируются по значению индикатора, и его наибольшее значение принимается равным 1, следующее за ним - 2 и т. д. Ранжирование произведено по долям объектов с установленными границами и долям всех объектов каждого региона в их общем количестве по округу. Показатель вычисляется как среднее арифметическое значение двух рейтингов по каждому субъекту. 
В связи с тем, что применённый метод недостаточно точно отражает ситуацию, и по трём регионам показатели оказались равны друг другу $(3,5)$, был применён метод «максимум-минимум», при котором приравниваются минимальные и максимальные значения по всем частным показателям, что приводит к уничтожению различий в их разбросе [8]. Трансформируемые показатели рассчитывались по формуле:

$$
\bar{X}=\frac{x-x_{\min }}{x_{\max }-x_{\min }}
$$

где $x_{\max }$ - максимальное значение показателя, $x_{\min }-$ минимальное значение показателя.

Таблица 2

\section{Показатели ИКК в части установления границ объектов}

\begin{tabular}{|c|c|c|c|c|c|}
\hline $\begin{array}{c}\text { Наименование } \\
\text { региона } \\
\text { (субъекта РФ) }\end{array}$ & $\begin{array}{c}\text { Доля земельных } \\
\text { участков и ОКС, } \\
\text { для которых } \\
\text { установлены } \\
\text { границы, \% }\end{array}$ & $\begin{array}{c}\text { Кол-во } \\
\text { обённых }\end{array}$ & $\begin{array}{c}\text { Доля уч- } \\
\text { тенных } \\
\text { объектов в } \\
\text { целом по } \\
\text { СФО, \% }\end{array}$ & $\begin{array}{c}\text { Сравнительный } \\
\text { интегральный } \\
\text { показатель ИКК } \\
\text { по рейтинговому } \\
\text { методу }\end{array}$ & $\begin{array}{c}\text { Уточненный (пер- } \\
\text { вый) показатель ИКК } \\
\text { по установлению } \\
\text { границ объектов } \\
\text { недвижимости, \% }\end{array}$ \\
\hline Омская область & 31,5 & 1384323 & 10,1 & 8,0 & 23 \\
\hline Томская область & 36,7 & 722969 & 5,3 & 7,0 & 61 \\
\hline $\begin{array}{c}\text { Новосибирская } \\
\text { область }\end{array}$ & 49,9 & 1851364 & 13,5 & 3,5 & 56 \\
\hline Алтайский край & 39,7 & 2408841 & 17,6 & 3,0 & 13 \\
\hline $\begin{array}{c}\text { Республика } \\
\text { Алтай }\end{array}$ & 39,4 & 316783 & 2,3 & 7,0 & 50 \\
\hline $\begin{array}{c}\text { Республика } \\
\text { Хакасия }\end{array}$ & 35,8 & 525132 & 3,8 & 8,0 & 60 \\
\hline Республика Тыва & 62,7 & 228229 & 1,7 & 5,5 & 56 \\
\hline $\begin{array}{c}\text { Кемеровская } \\
\text { область }\end{array}$ & 33,9 & 1903439 & 13,9 & 6,0 & 36 \\
\hline $\begin{array}{c}\text { Красноярский } \\
\text { край }\end{array}$ & 37,9 & 2795835 & 20,4 & 3,5 & - \\
\hline $\begin{array}{c}\text { Иркутская } \\
\text { область }\end{array}$ & 50,9 & 1539222 & 11,3 & 3,5 & - \\
\hline ИТОГО: & 40,5 & 13676137 & 100 & - & 5 \\
\hline
\end{tabular}

Уточнённые результаты по регионам с вышеупомянутыми равными друг другу показателями в связи с применением более точного метода их расчётов позволяют определить субъекты с наилучшей ситуацией по изучаемой проблеме (Новосибирская область) и наихудшей (Республика Хакасия) в Сибирском федеральном округе. Исходя из этого, можно сделать выводы о субъектах СФО относительно состояния развития их территорий по группе проблем, характеризуемой рассчитанным показателем. В связи с этим приведённые результаты характеризуют изучаемые регионы как минимум по двум направлениям:

- по масштабам неоспоримости местоположения объектов недвижимости, и, как следствие, по инвестиционной привлекательности этих объектов, которая связана с отсутствием возможности утраты части объекта (например, земельного участка), отсутствием перспектив судебных расходов при спорах о достоверности местоположения и пр.;

- по корректности кадастровой стоимости недвижимости, в части, зависящей от достоверности её пространственного описания, а, следовательно, о корректности и правомерности налогообложения объектов недвижимости.

Вторым рассматриваемым показателем ИКК является официально подтверждаемый объём выбытий земель лесного фонда по изучаемым субъектам. В целом по России с момента начала реализации закона о «лесной амнистии» площадь лесных участков в данных ЕГРН к маю 2020 га уменьшена на 136 млн га [9]. Это связано с тем, что были устранены пересечения границ лесных участков между собой и с границами земельных участков иных категорий земель, исключены дублирующие сведения 
о лесных участках, лесные участки были включены в границы населенных пунктов и пр. Как уже было отмечено выше, более 10 млн га из вышеуказанной общероссийской площади приходится на Иркутскую область.

При этом в докладе о состоянии и использовании земель в Иркутской области за 2019 г. региональное управление Росреестра данные сведения не отражает, по сравнению с предыдущим годом площадь земель лесного фонда в официальной отчётности уменьшилась только на 4,2 тыс. га [10]. По территории регионов Сибирского федерального округа аналогичное расхождение в сопоставлении 2018-2019 гг. либо не превышает указанного значения (Красноярский край, Томская область, Республика Хакасия), либо сведения в открытом доступе (официальный сайт Росреестра ${ }^{10}$ ) не отражены. В связи с имеющимися противоречиями и неполнотой в сведениях государственной статистики, по изучаемому параметру провести качественный анализ не представляется возможным.

Третий искомый показатель ИКК - доля многоквартирных домов, расположенных на земельных участках, в отношении которых осуществлен государственный кадастровый учет, нормативно интегрирован в систему государственной статистики. Соответствующие статистические наблюдения ведутся на муниципальном уровне в каждом регионе, в связи с чем по заданному направлению в качестве объектов исследования были выбраны муниципалитеты Иркутской области.

Применительно к Иркутской области исследуемый индикатор территориально дифференцируется по муниципальным образованиям региона в процентном отношении, как это приведено на рис. 3. При этом по двенадцати муниципальным образованиям области - Балаганскому, Катангскому, Качугскому, Киренскому, Куйтунскому, Тайшетскому, Боханскому, Нукутскому, Осинскому, Нижнеудинскому, Иркутскому и Усольскому районам - статистика отсутствует.

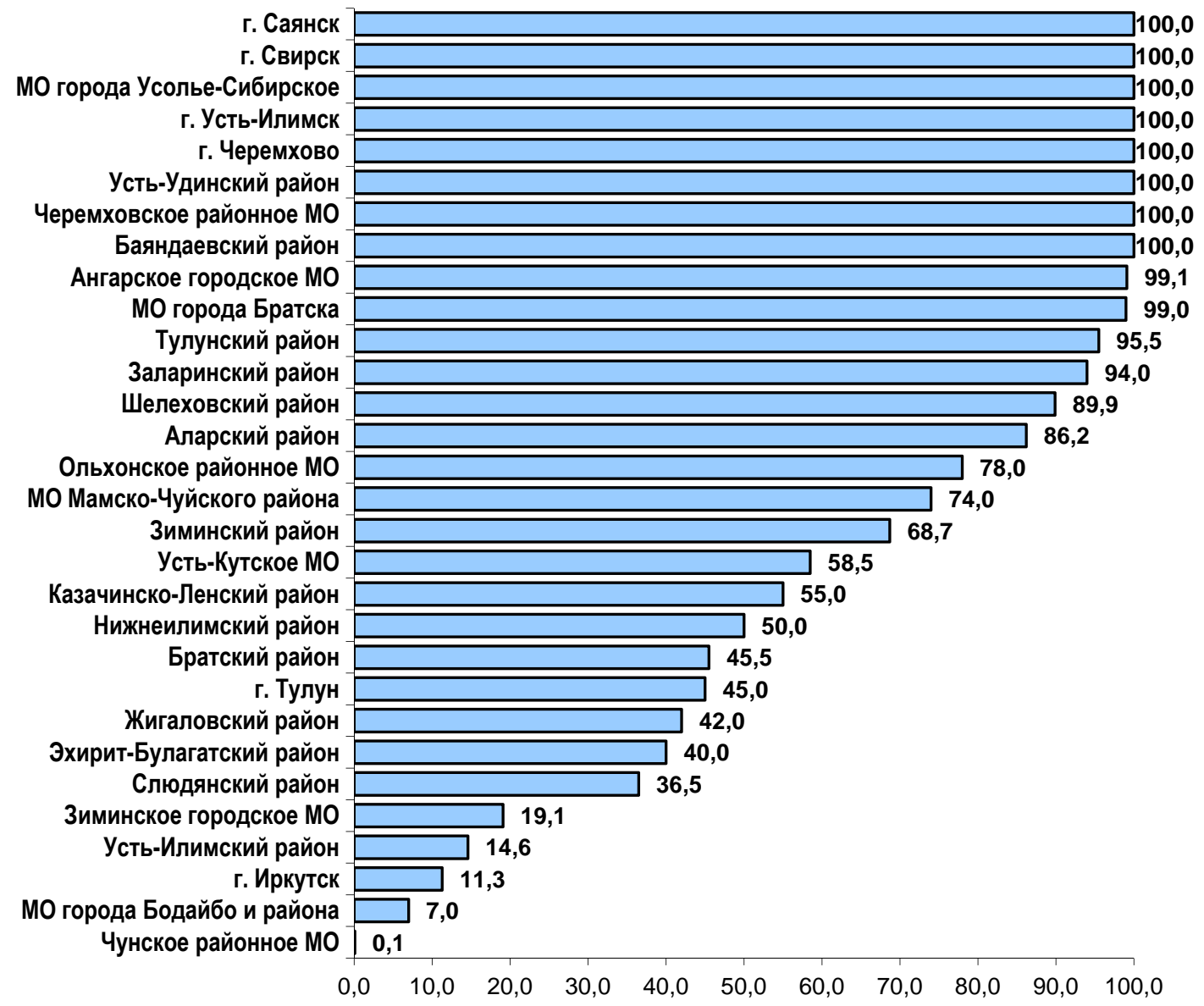

Рис. 3. Доля многоквартирных домов, расположенных на земельных участках, в отношении которых осуществлен государственный кадастровый учет, по состоянию на конец 2019 г. (\%) [11]

\footnotetext{
${ }^{10}$ URL: https://rosreestr.ru/, раздел «Статистика и аналитика».
} 
Поскольку принцип, примененный при расчёте первого показателя ИКК, можно масштабировать на муниципальные образования, так как кадастровое деление территории регионов осуществляется главным образом по их границам, существует возможность качественной интеграции третьего и первого показателей между собой, используя ранее примененный методологический аппарат.

Таким образом, ИКК можно будет охарактеризовать интегрированным показателем, включающим в себя долю объектов учёта с установленными границами и долю многоквартирных домов, расположенных на земельных участках, в отношении которых осуществлен государственный кадастровый учет, в рамках конкретного муниципального образования. С учётом имеющихся в наличии данных в качестве результата данного исследования будет получен комплексный показатель ИКК муниципальных образований (МО) Иркутской области.

\section{Результаты и их обсуждение}

В табл. 3 приведены результаты расчётов комплексного показателя ИКК отдельных муниципальных образований Иркутской области, которые получены рейтинговым методом и методом максимум-минимум. Для определения финальной характеристики информативности кадастрового картографирования территорий проведено ранжирование по наиболее информативному показателю.

Показатели ИКК по отдельным муниципальным образованиям Иркутской области

Таблица 3

\begin{tabular}{|c|c|c|c|}
\hline $\begin{array}{c}\text { Наименование } \\
\text { муниципального образования }\end{array}$ & $\begin{array}{c}\text { Сравнительный } \\
\text { интегральный } \\
\text { показатель ИКК по } \\
\text { рейтинговому методу }\end{array}$ & $\begin{array}{c}\text { Комплексный } \\
\text { (интегральный) показатель } \\
\text { при «максминном» методе } \\
\text { трансформации частных } \\
\text { индикаторов, \% } \\
\end{array}$ & $\begin{array}{c}\text { Ранг } \\
\text { комплексного } \\
\text { показателя }\end{array}$ \\
\hline Ангарское городское МО & 2,7 & 90,1 & 1 \\
\hline Тулунский район & 6,3 & 80,2 & 2 \\
\hline Черемховское районное МО & 8,7 & 76,4 & 3 \\
\hline Шелеховский район & 7,7 & 74,5 & 4 \\
\hline г. Усть-Илимск & 8,0 & 72,1 & 5 \\
\hline $\begin{array}{c}\text { г. Черемхово и г. Свирск (входят } \\
\text { в один кадастровый район) }\end{array}$ & 8,0 & 70,1 & 6 \\
\hline Заларинский район & 11,0 & 69,4 & 7 \\
\hline МО города Усолье-Сибирское & 8,3 & 68,7 & 8 \\
\hline МО города Братска & 11,3 & 66,4 & 9 \\
\hline г. Иркутск & 8,7 & 65,9 & 10 \\
\hline Баяндаевский район & 11,0 & 65,1 & 11 \\
\hline Аларский район & 12,7 & 63,1 & 12 \\
\hline Братский район & 10,7 & 61,7 & 13 \\
\hline Ольхонское районное МО & 10,0 & 61,6 & 14 \\
\hline Нижнеилимский район & 10,0 & 58,8 & 15 \\
\hline г. Саянск & 14,0 & 58,3 & 16 \\
\hline Зиминский район & 14,7 & 55,9 & 17 \\
\hline Усть-Кутское МО & 14,3 & 55,0 & 18 \\
\hline Слюдянский район & 13,7 & 48,9 & 19 \\
\hline Жигаловский район & 14,3 & 46,5 & 20 \\
\hline Эхирит-Булагатский район & 17,0 & 45,4 & 21 \\
\hline г. Тулун & 17,0 & 44,2 & 22 \\
\hline Казачинско-Ленский район & 18,7 & 42,4 & 23 \\
\hline Усть-Удинский район & 17,3 & 39,8 & 24 \\
\hline МО Мамско-Чуйского района & 22,0 & 35,7 & 25 \\
\hline Усть-Илимский район & 19,0 & 32,6 & 26 \\
\hline Зиминское городское МО & 19,7 & 32,5 & 27 \\
\hline Чунское районное МО & 21,7 & 24,3 & 28 \\
\hline МО города Бодайбо и района & 25,7 & 17,0 & 29 \\
\hline
\end{tabular}


Учитывая проблемную обусловленность найденных по итогам исследования значений, полученные результаты должны отражать следующие качественные составляющие развития территорий изученных муниципальных образований:

- неоспоримость местоположения объектов недвижимости, повышающую их привлекательность в качестве ликвидных активов;

- корректность кадастровой стоимости объектов в части достоверности сведений об их местоположении, обеспечивающую обоснованное и легитимное налогообложение граждан и организаций;

- корректность уточненных границ объектов недвижимости, частично дополняющую два предыдущих критерия качества развития территории.

Однако значение комплексного показателя, полученного в отношении, например, областного центра Иркутской области, вызывает определённые сомнения относительно возможности его самостоятельного применения при анализе экономики территорий, без учёта иных показателей состояния её развития. Так, значение комплексного показателя по городу Иркутску практически равно его значению по Баяндаевскому муниципальному району, расположенному в сельской местности, и объективно несопоставимому по ликвидности недвижимых активов с административным и экономическим центром региона.

Помимо указанного противоречия, при оценке полученных результатов относительно третьего показателя ИКК, необходимо учитывать особенности применённых для его расчёта сведений. Эти особенности состоят в ограниченности объёма имеющихся статистических данных, их узкоспециализированном характере и невысокой релевантности с поставленной группой проблем, что в целом не способствует высокой достоверности описания качества территориального развития. В связи с чем, представляется целесообразным в дальнейшем при ведении аналогичных исследований уточнять содержательную сторону данного показателя в направлении устранения недостатков исходных данных, применяемых при его расчёте.

\section{Заключение}

Проведенное исследование выявило, что проблемно обусловленные показатели информативности кадастрового картографирования можно вычислять по довольно ограниченной группе проблем, косвенно характеризующихся этими показателями. Так, предложенный социально и экономически значимый показатель ИКК, отражающий качество данных кадастра применительно к землям лесного фонда, на сегодняшний день не может определяться повсеместно, в связи с противоречиями и неполнотой в сведениях государственной статистики, по изучаемому параметру.

Относительно показателя ИКК, использованного для оценки территории по критерию «количество некорректных уточнений границ», также имеются сложности в части повсеместности применения. Это связано с тем, что индикатор ИКК по данному критерию зависит от наличия на изучаемой территории многоквартирных домов (и их количества), которые могут отсутствовать в конкретном ареале исследований.

Показатель ИКК, описывающий количество уточненных (установленных) границ, наиболее репрезентативно (из рассмотренных) отражает изучаемую характеристику территорий. Данный индикатор в ходе трансформации и интеграции с предыдущим позволяет определить уровень качества развития территории с точки зрения информативности пространственных сведений, содержащихся в кадастре недвижимости. При этом анализ результатов расчёта показателя по отдельным муниципалитетам Иркутской области выявил, что его содержательная наполненность нуждается в пересмотре по части состава исходных данных, применяемых при расчётах.

Таким образом, сформулированный и использованный в настоящей работе комплексный показатель информативности кадастрового картографирования целесообразно применять при анализе качества территориального развития совместно с другими сопоставимыми показателями, после доработки состава количественных индикаторов, формирующих содержание комплексного показателя ИКК.

\section{СПИСОК ЛИТЕРАТУРЫ}

1. Пояснительная записка к проекту Постановления Правительства Российской Федерации «О проведении в 2020 году эксперимента по созданию единого информационного ресурса о земле и недвижимости». URL: https://regulation.gov.ru/projects\#npa=101659 (дата обращения: 30.04.2020). 
2. Карпик А.П., Федоренко Ю.В., Пархоменко Д.В. О роли геоинформации в решении гражданско-правовых проблем на основе Единого государственного реестра недвижимости (на материалах Иркутской области) // Вестн. СГУГиТ (Сибирского государственного университета геосистем и технологий). 2017. Т. 22 , № 2. C. 154-170.

3. Совет Федерации принял законы о «лесной амнистии» и о ведении садоводства и огородничества. URL: https://www.kommersant.ru/doc/3367667 (дата обращения: 28.05.2020).

4. Более 10 млн га земель вывели из лесного фонда Иркутской области по амнистии / Интефакс. Сибирь. URL: http://www.interfax-russia.ru/Siberia/report.asp?id=1087664 (дата обращения: 09.12.2019).

5. Степанов К.Г. Ограниченность объема сведений кадастрового учета как деструктивный фактор развития территорий особого градостроительного регулирования (на примере территории Академгородка г. Иркутска) // Проблемы государственной регистрации недвижимости и кадастрового учета: материалы V науч.практ. конф. (г. Иркутск, 3 декабря 2019 г.). Иркутск, 2020. С. 55-60.

6. Региональный доклад о состоянии и использовании земель в Иркутской области за 2018 год / Управление Росреестра по Иркутской области. Иркутск, 2019. 110 С.

7. Объем заготовленной древесины / EMИСС Государственная статистика. URL: https:/www.fedstat.ru/ indicator/37848 (дата обращения: 04.06.2020).

8. Васильева Л.В. Анализ методических подходов к построению интегральных экономических показателей // Экономические исследования и разработки. 2017. № 12. С. 9.

9. Росреестр. Росреестр подвёл итоги реализации «лесной амнистии» за первый квартал 2020 года. URL: https://rosreestr.ru/site/press/news/rosreestr-podvyel-itogi-realizatsii-lesnoy-amnistii-za-pervyy-kvartal-2020-goda-/ (дата обращения: 05.06.2020).

10. Региональный доклад о состоянии и использовании земель в Иркутской области за 2019 год / Управление Росреестра по Иркутской области. Иркутск, 2020. 120 с.

11. Рейтинговая оценка эффективности деятельности органов местного самоуправления / Иркутскстат: ст. сб. Иркутск, 2020. 57 с.

Поступила в редакцию 12.11.2020

Степанов Константин Геннадьевич, младший научный сотрудник

Иркутского научного центра Сибирского отделения РАН

664033, Россия, г. Иркутск, ул. Лермонтова, 134,

аспирант ФГБНУ «Институт географии им. В.Б. Сочавы СО РАН»

664033, Россия, г. Иркутск, ул. Улан-Баторская, 1

E-mail: skg@isc.irk.ru.

\section{K.G. Stepanov \\ INFORMATIVENESS OF CADASTRAL MAPPING AS AN INDICATOR OF THE QUALITY OF TERRITORIAL DEVELOPMENT}

DOI: $10.35634 / 2412-9518-2020-30-4-484-495$

The article considers the possibility of analyzing the quality of territorial development through the use of a specialized indicator of information content of cadastral mapping. To do this, the author defines the content of this indicator, justifies its applicability to achieve the goal by revealing the problematic conditionality of its components, and offers a list of specific indicators that can be integrated into the desired indicator. In the role of characteristics of the quality of territorial development, the study identifies the aggregate positive properties of real estate objects that they acquire with high values of information content of cadastral mapping. The corresponding characteristics are described by an indicator calculated by two different methods, one of which is selected as the most optimal, due to its greater information content. The results obtained by calculation are analyzed for their representativeness and the possibility of independent application for studying the state of development of the territory. Based on the final conclusions, the author puts forward the thesis that the complex indicator of information content of cadastral mapping formulated and used in this work should be used when analyzing the quality of territorial development together with other comparable indicators, after finalizing the composition of quantitative indicators that form the content of the described complex indicator.

Keywords: cadastral mapping, calculation of integral indicators, quality of territorial development, economic properties of real estate. 


\section{REFERENCES}

1. Poyasnitel'naya zapiska k proektu Postanovleniya Pravitel'stva Rossiiskoi Federatsii «O provedenii v 2020 godu eksperimenta po sozdaniyu edinogo informatsionnogo resursa o zemle i nedvizhimosti» [Explanatory note to the draft decree of the Government of the Russian Federation «On conducting an experiment in 2020 to create a single information resource on land and real estate»], Available at: https://regulation.gov.ru/projects\#npa=101659 (accessed 30.04.2020) (in Russ.).

2. Karpik A.P., Fedorenko Yu.V., Parkhomenko D.V. [About the role of geoinformation in solving civil law problems based on the Unified state register of real estate (based on the materials of the Irkutsk region)], in Vestnik SGUGiT (Sibirskogo Gos. Univ. Geosistem i Tekhnologiy) [Vestnik of SSUGT (of Siberian State University of Geosystems and Technologies)], 2017, vol. 22, no. 2, pp. 154-170 (in Russ.).

3. Sovet Federatsii prinyal zakony o "lesnoi amnistii» $i$ o vedenii sadovodstva $i$ ogorodnichestva [The Federation Council adopted the laws on "forest Amnesty" and the gardening and horticulture], Available at: https://www.kommersant.ru/doc/3367667 (accessed 28.05.2020) (in Russ.).

4. Bolee $10 \mathrm{mln}$ ga zemel' vyveli iz lesnogo fonda Irkutskoi oblasti po amnisti, Sayt Intefaks. Sibir' [More than 10 million hectares of land were removed from the forest Fund of the Irkutsk region under an Amnesty / Website of the Interfax-Siberia] [Electronic resource], Available at: http://www.interfax-russia.ru/Siberia/report.asp?id=1087664 (accessed 09.12.2019) (in Russ.).

5. Stepanov K.G. [Limited amount of cadastral data as a destructive factor in the development of territories of special urban planning regulation (on the example of the territory of Akademgorodok, Irkutsk)], in Mater. V nauch.-prakt. konf. "Problemy gosudarstvennoi registratsii nedvizhimosti i kadastrovogo ucheta" (Irkutsk, 3 dekabrya, 2019) [Problems of state registration of real estate and cadastral registration: materials of the $\mathrm{V}$ scientific-practical conference (Irkutsk, December 3, 2019)], Irkutsk, 2020, pp.55-60 (in Russ.).

6. Regional'nyi doklad o sostoyanii i ispol'zovanii zemel'v Irkutskoi oblasti za 2018 god / Upravlenie Rosreestra po Irkutskoi oblasti [Regional report on the state and use of land in the Irkutsk region for 2018 / Department of the Federal registration service for the Irkutsk region], Irkutsk, 2019. 110 p. (in Russ.).

7. Ob"em zagotovlennoi drevesiny, Sayt EMISS gosudarstvennaya statistika [Volume of harvested wood / Website of the Federal State Statistic Service] [Electronic resource], Available at: https://www.fedstat.ru/indicator/37848 (accessed 04.06.2020) (in Russ.).

8. Vasil'eva L.V. [Analysis of methodological approaches to the construction of integrated economic indicators], in Ekonomicheskie issledovaniya i razrabotki [Economic development research journal], 2017, no. 12, p. 9 (in Russ.).

9. Rosreestr podvel itogi realizatsii «lesnoi amnistii» za pervyi kvartal 2020 goda, Sayt Federal'noy sluzhby gosudarstvennoy registratsii, kadastra i kartografii (Rosreestr) [Rosreestr summed up the implementation of the "forest Amnesty" for the first quarter of 2020 / Website of the Federal service for state registration, cadaster and cartography (Rosreestr)], Available at: https://rosreestr.ru/site/press/news/rosreestr-podvyel-itogi-realizatsii-lesnoyamnistii-za- pervyy-kvartal-2020-goda-/ (accessed 05.06.2020) (in Russ.).

10. Regional'nyi doklad o sostoyanii i ispol'zovanii zemel' v Irkutskoi oblasti za 2019 god / Upravlenie Rosreestra po Irkutskoi oblasti [Regional report on the state and use of land in the Irkutsk region for 2019 / Department of the Federal registration service for the Irkutsk region], Irkutsk, 2020. 120 p. (in Russ.).

11. Reitingovaya otsenka effektivnosti deyatel'nosti organov mestnogo samoupravleniya. Statisticheskii sbornik / Irkutskstat [Rating assessment of the effectiveness of local government bodies. Statistical compendium / Irkutskstat], Irkutsk, 2020, 57 p. (in Russ.).

Stepanov K.G., Junior researcher

Irkutsk Scientific Center SB RAS,

Lermontova st., 134, Irkutsk, Russia, 664033

postgraduate student

Institute of geography of SB RAS, named after V.B. Sochava

Ulan-Batorskaya st., 1, Irkutsk, Russia, 664033

E-mail: skg@isc.irk.ru 